\title{
Starch Wastewater Treatment in a Three Phase Fluidized Bed Bioreactor with Low Density Biomass Support
}

\author{
*RAJASIMMAN, M; KARTHIKEYAN, C \\ Environmental Engineering Laboratory, Department of Chemical Engineering, Annamalai University \\ Annamalai Nagar - 608002, Tamil nadu, India.
}

\begin{abstract}
Aerobic digestion of starch industry wastewater was carried out in an inverse fluidized bed bioreactor using low density $\left(870 \mathrm{~kg} / \mathrm{m}^{3}\right)$ polypropylene particles. Experiments were carried at different initial substrate concentration of $2250,4475,6730$ and $8910 \mathrm{mg} \mathrm{COD} / \mathrm{L}$ and for various hydraulic retention time 40,32, 24, 16 and $8 \mathrm{~h}$. Degradation of organic matter was studied at different organic loading rate by varying the hydraulic retention time and initial substrate concentration. From the results it was observed that the maximum COD removal of $95.6 \%$ occurs at an organic loading rate of $1.35 \mathrm{~kg} \mathrm{COD} / \mathrm{m}^{3} / \mathrm{d}$ and a minimum of $51.8 \%$ at an OLR of $26.73 \mathrm{~kg} \mathrm{COD} / \mathrm{m}^{3} / \mathrm{d}$. The properties of biomass accumulation on the surface of particles were also studied. It was observed that a constant biomass loading was achieved over the entire period of operation. @JASEM
\end{abstract}

$\sigma$ - Biofilm thickness, cm

$\mathrm{r}_{\mathrm{p}}$ - Support particle radius, $\mathrm{cm}$

$\rho_{\mathrm{p}}$ - Density of the particle, $\mathrm{g} / \mathrm{cc}$

$\mathrm{d}_{\mathrm{p}}$ - Diameter of the particle, $\mathrm{cm}$

$\mathrm{d}_{\mathrm{b}}$ - Diameter of the bioparticle, $\mathrm{cm}$

\section{Nomenclature}

$\mathrm{M}_{\mathrm{s}}$ - Mass of the support particles, $\mathrm{g}$

A - Surface area of particles, $\mathrm{cm}^{2}$

$\mathrm{H}$ - bed height, $\mathrm{cm}$

$\rho_{\mathrm{b}}-$ Bio particle density, $\mathrm{g} / \mathrm{cc}$

$\rho_{\mathrm{bw}}-$ Biofilm Density considered as $1 \mathrm{~g} / \mathrm{cc}$
During the past few years the application of fluidization has increased considerably in the field of chemical, biochemical engineering and in wastewater treatment. It has many advantages over fixed bed reactors (Sokol, 2001). The limitation of the fluidized bed reactor in wastewater treatment is the biofilm thickness. There is a problem of increase in biofilm thickness when the microorganisms in the biofilm multiply. This limits diffusion of oxygen and / or the organic substrate to the deeper layers of the biofilm. Starvation of the microorganisms at the base of the biofilm causes pieces of the biofilm to detach and leads to ineffective bioreactor operation. The maximum biofilm thickness at which no diffusional limitation is observed is usually around $100 \mu \mathrm{m}$. Therefore to operate the bioreactor efficiently, the biofilm thickness should be approximately $100 \mu \mathrm{m}$. In order to maintain a constant biofilm thickness, the particles are taken out and the excess biofilm is removed and particles are sent to the reactor. The use of IFBBR can solve this problem (Karamanev and Nikolov, 1996).

The inverse fluidization is a multiphase gas-liquidsolid system. The difference between ordinary fluidization and inverse fluidization lies in the density of solid particles used in the reactor. If the density of the particles used is greater than the fluid, it is ordinary fluidization; if it is less than fluid it is called as inverse fluidization. The use of low-density particles has some advantages and overcomes the problem, which occurs during conventional fluidization. Low-density particles require low fluid velocity for their expansion and hence low power requirement. In IFBBR, the control of biofilm thickness is achieved within a narrow range (Karamanev, 1987). The particle-particle and particle wall collision maintains a constant biofilm thickness (Sokol, 2001). The present study aims to investigate the feasibility of an inverse fluidized bed bioreactor for the treatment of starch industry wastewater.

\section{MATERIALS AND METHODS}

The experimental set up of the inverse fluidized bed bioreactor (IFBBR) was shown in Figure 1. Reactor was made up of Perspex column and has the dimensions of $9.6 \mathrm{~cm}$ internal diameter, $220 \mathrm{~cm}$ height and a wall thickness of $0.4 \mathrm{~cm}$. The bottom was conical in order to facilitate easy removal of solids settled in the reactor. The total volume of the reactor was $16 \mathrm{~L}$. A vent was provided at the middle of the reactor for the easy loading and unloading of the particles from the reactor. Meshes were placed $30 \mathrm{~cm}$ from both top and bottom of the reactor to prevent the elutriation of particles and to retain the particles during shut down periods. A hand woven nylon mesh was used for this purpose. The supporting particles used in this study were made of polypropylene with a density of $870 \mathrm{~kg} / \mathrm{m}^{3}$. It is 
irregular in shape with a diameter of $10 \mathrm{~mm}$ and surface area of $390 \mathrm{~mm}^{2} / \mathrm{mm}^{3}$.

The reactor was filled with the supporting material to give $80 \mathrm{~cm}$ initial bed height from the supporting mesh. The substrate was starch industry wastewater. The inoculum was prepared from the sludge taken from the starch industry effluent treatment plant. It was introduced into the reactor along with the support particles and substrate, to start the growth of microorganisms on the surface of supporting materials. Since the wastewater was deficient of phosphorous and nitrogen small quantity of potassium phosphate and ammonium chloride are added to the wastewater as per requirement (Nehru Kumar, 2001). Air is supplied at the rate of 11.11 $\mathrm{cc} / \mathrm{s}$, which is sufficient for biomass growth and $\mathrm{pH}$ was maintained between 5.9 and 6.1. It was found that a $\mathrm{pH}$ value of 6 is optimum for the better degradation of starch wastewater using the sludge (Rajasimman and Karthikeyan, 2004). The set up was left for 20 days with aeration in order to enhance microbial film formation on the low-density support particle. After the completion of biofilm formation, the liquid medium inside the reactor was withdrawn leaving the biomass-laden particles. Then the substrate was pumped into the reactor and air was supplied at the same rate.

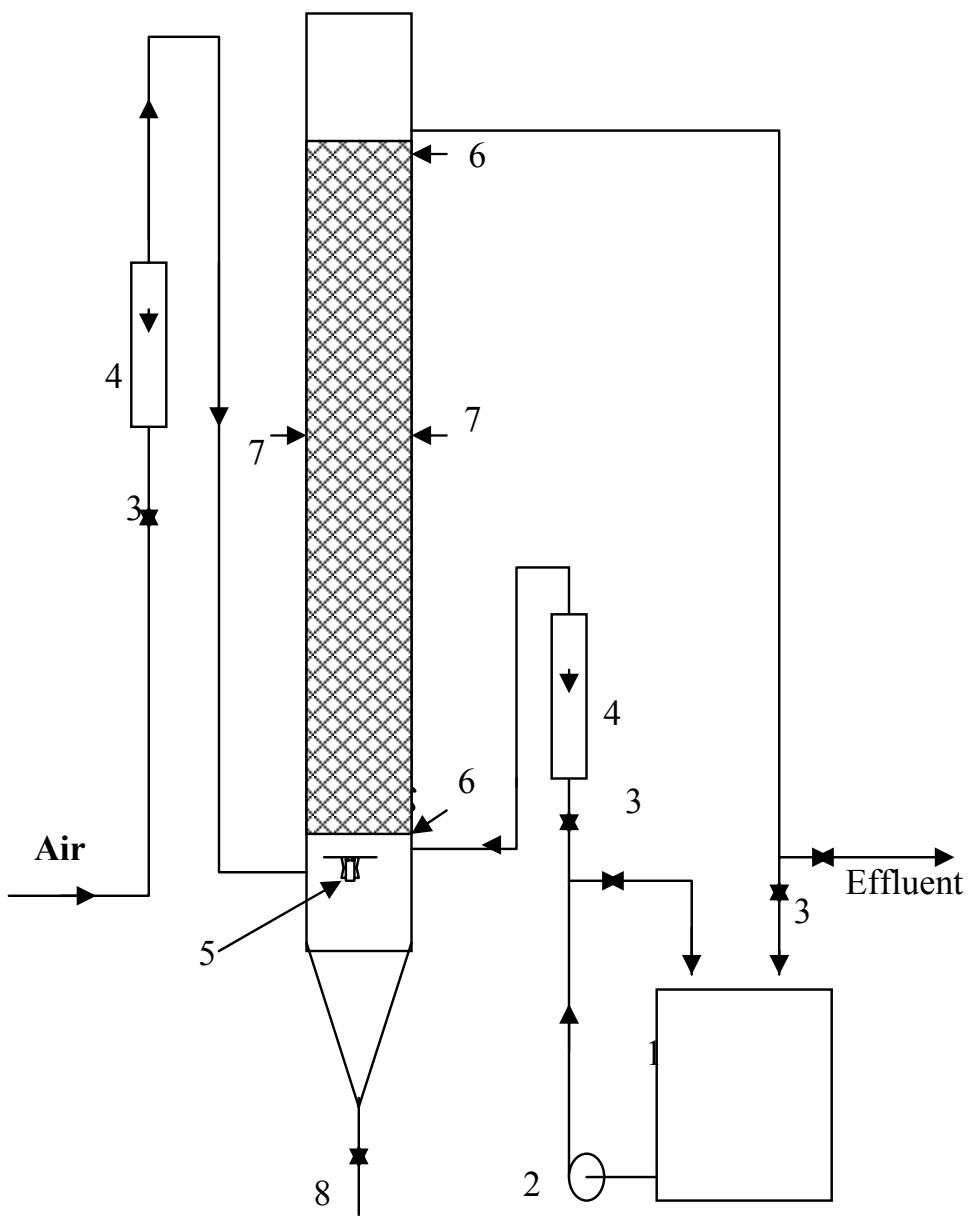

Fig.1 Inverse Fluidized Bed Bioreactor

1.Storage tank. 2.Centrifugal pump. 3.Valves. 4.Rotameter. 5.Air

Sparger. 6.Supporting mesh. 7.Fluidizing section. 8.Discharge valve.

Biomass growth on the low-density particles, in the reactor was continuously monitored. The particles covered by biofilm were taken out and the attached volatile solid (dry weight) was found out. The difference between two weights was considered as the attached volatile solid that corresponds to the biomass weight (Garcia-Calderon et al., 1998). Bioparticles samples were withdrawn from top, 
middle and bottom of the reactor, because at the bottom of the reactor the density of the particles were found to be more when compared with the middle and top section of the reactor. This is due to the growth of biofilm on the surface of the particles and it is also an added advantage because the substrate concentration is more at the bottom. The biofilm thickness is calculated by the equation (Nikolov and Karamanev, 1990)

$$
\sigma=\left[\frac{\left[\frac{M_{S}}{4 \pi r_{p}{ }^{2}}-\frac{r_{p} \rho_{p}}{3}\right]}{\rho_{b w}}\right]
$$

Bioparticle diameters are calculated according to Setiadi, (1995)

$$
d_{b}=\sqrt{\frac{d_{p}^{3}(1-\varepsilon)}{\left(\frac{M_{s}}{\rho_{b} H A}\right)}}
$$

Biofilm thickness and bio particle density are determined based on the equations (Sheikh et al., 1981)

$$
\begin{aligned}
& d_{b}=d_{p}+2 \sigma \\
& \rho_{b}=\rho_{m}\left(\frac{d_{p}}{d_{b}}\right)^{3}+\rho_{b w}\left[1-\left(\frac{d_{p}}{d_{b}}\right)^{3}\right] . .4
\end{aligned}
$$

Degradation of starch wastewater in IFBBR was carried out continuously in different stages by varying initial substrate concentration $(2250,4475$, 6730 and $8910 \mathrm{mg} \mathrm{COD} / \mathrm{L})$ and hydraulic retention time (40, 32, 24, 16 and $8 \mathrm{~h})$. Degradation was started with an initial concentration of $2250 \mathrm{mg} \mathrm{COD} / \mathrm{L}$ and a HRT of $40 \mathrm{~h}$. The reactor was monitored continuously by measuring effluent COD values. When the reactor reaches steady state, the HRT was reduced to $32 \mathrm{~h}$ and reduction in COD was monitored. Experiment was continued with various HRT $(24,16$ and $8 \mathrm{~h})$. The performance of the reactor was studied based on COD removal efficiency. Experiment was repeated for various initial substrate concentrations at five different HRT by maintaining an optimum bed height and air flow rate. The $\mathrm{pH}$ of the influent to the reactor was maintained at 6.0

\section{RESULTS AND DISCUSSION}

The performance of the IFBBR for the biodegradation of starch industry wastewater was studied in this work. All the studies were carried out at a bed height of $80 \mathrm{~cm}$ and at constant air flow rate of $62.50 \mathrm{cc} / \mathrm{s}$, which is optimum for the maximum degradation rate (Rajasimman and Karthikeyan, 2006). The influent and effluent concentration of the reactor for the average initial substrate concentration of $2250 \mathrm{mg} \mathrm{COD} / \mathrm{L}$ was shown in Figure 2. Initially the reactor was started with an organic loading rate (OLR) of $1.35 \mathrm{~kg} \mathrm{COD} / \mathrm{m}^{3} / \mathrm{d}$. During the initial stage, percentage COD reduction was found to be low due to the fact that microbes need longer time for acclimatization. The maximum COD reduction of $95.6 \%$ occurs at the thirteenth day from the experiment start up period. The effect of OLR was investigated by varying HRT while maintaining the concentration of the influent constant. The HRT were varied from $40 \mathrm{~h}$ to $8 \mathrm{~h}$. Organic loading rate was increased to $1.69 \mathrm{kgCOD} / \mathrm{m}^{3} / \mathrm{d}$ by reducing HRT from $40 \mathrm{~h}$ to $32 \mathrm{~h}$ on fourteenth day and the reactor performance was monitored regularly by measuring effluent COD from the reactor. The reactor reached steady state within seven days of operation and the reduction in COD was found to be $94.7 \%$.

After reaching the steady state, the OLR was increased to $2.25 \mathrm{kgCOD} / \mathrm{m}^{3} / \mathrm{d}$ by reducing the HRT to $24 \mathrm{~h}$ and the percentage COD reduction was found to be $93.9 \%$ after 34 days. Then the HRT was decreased to $16 \mathrm{~h}$ and the maximum degradation of $87.5 \%$ was occurred at the $46^{\text {th }}$ day. Although there is an instantaneous increase in the OLR while decreasing the HRT, a low effluent COD level is recovered in a short period of time. Then the HRT was decreased to $8 \mathrm{~h}$ and the maximum percentage removal of $\mathrm{COD}$ was found to be $72.8 \%$. It was inferred that at lower HRT the percentage COD reduction was found to be low. This may be due to inadequate time for the degradation of waste by the biomass. With decrease in HRT the percentage COD reduction is found to decrease. However a significant drop in percentage COD reduction occurs for the HRT between $16 \mathrm{~h}$ and $8 \mathrm{~h}$. It was also seen that there is no significant improvement in the degradation of organic matter above $24 \mathrm{~h}$ HRT. This is well in agreement with the findings of Choi et al., 1995. When the organic loading rate is increased, sudden decrease in COD removal efficiency is observed and recovers at relatively in short period of time.

In the next stages, the average initial substrate concentration of the influent was increased to 4475 , 6730 and $8910 \mathrm{mg} \mathrm{COD} / \mathrm{L}$ and the reactor performance was observed. The degradation trend observed for the other initial substrate concentrations were similar to low concentration effluent. During final stage of operation, for the shock load condition of $26.73 \mathrm{~kg} \mathrm{COD} / \mathrm{m}^{3} / \mathrm{d}$ with the HRT of $8 \mathrm{~h}$, the percentage removal was found to be very low $(51.8 \%)$. It was observed that a high amount of suspended matter present in the effluent leaving the reactor. The reactor exhibits a good stability to the variations in OLR and HRT (Arnaiz et al.,2005). 


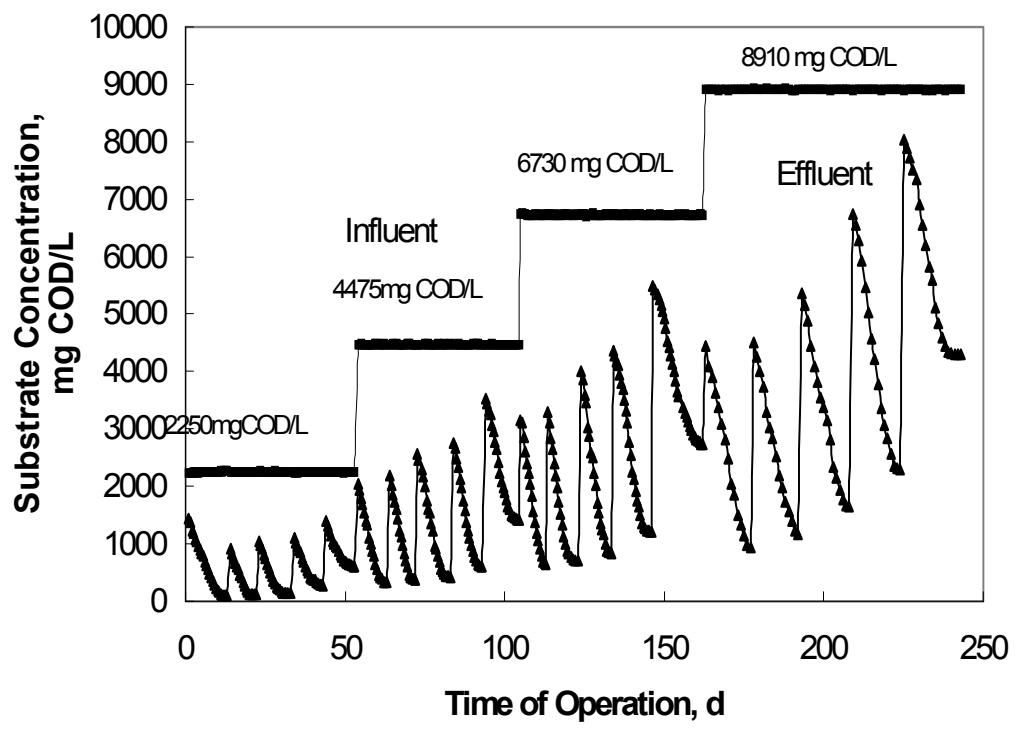

Fig.2 Variation of the effluent COD concentrations in response to the influent COD concentrations resulted by the variation of HRT and organic loading rate

Figure 3 shows the relationship between the organic loading rate and the COD removal efficiency for overall performance of the reactor. During the initial stages, at low organic loading rate, the removal efficiency was found to be high (>90\%). It was also observed that IFBBR has an excellent ability to overcome sudden disturbance in input organic loading. Some immediate decrease in COD removal efficiency is followed, but the high removal efficiency is recovered in a short period of time. In the Figure, for the same organic loading rate, a difference in percentage COD reduction was observed and it is due to the fact that the reactor is operated at different initial substrate concentrations.

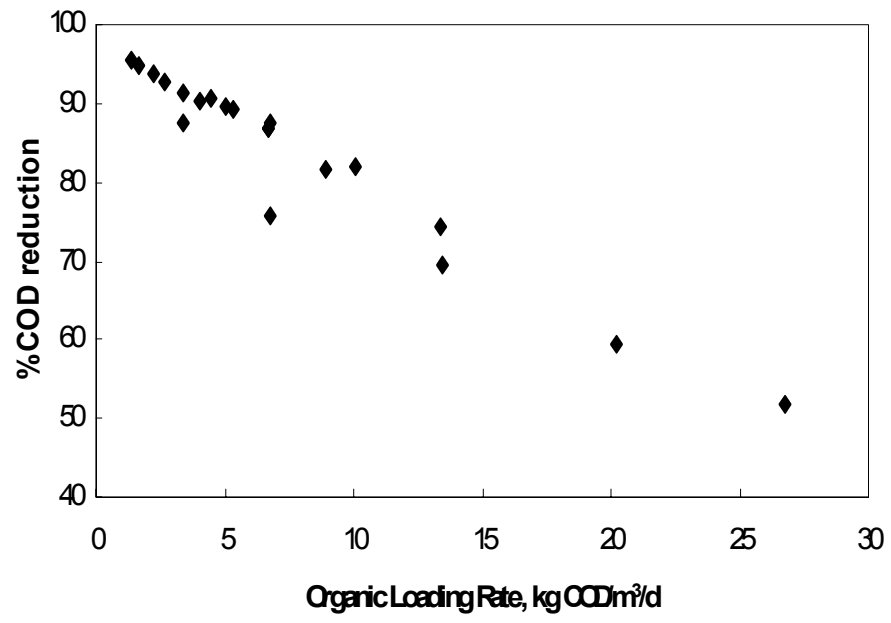

Fig.3 Effect of Organic Loading Rate on \%COD reduction
Biomass accumulation was measured by the increase of the attached volatile solids on polypropylene particles. Samples were taken at different heights of the reactor. At the upper part of the fluidized bed, the attached volatile solids concentration was always lesser than in the lower levels of the bed. Particles with thicker biofilm were found at the lowest level of the reactor, because particle terminal velocity decreases with biofilm accumulation. It was shown in Figure 4. Al-Dibouni and Garside (1979) considered particle dispersion in a fluidized bed to be influenced by several parameters: overall porosity, liquid superficial velocity, particle size, density, and shape. Figure 5 shows the biofilm development (average of the sample points), as well as the particle density at different organic loading rates. The biofilm formed was constant over the entire period of operation. The irregular surface of polypropylene particle allowed an increased biomass hold-up and the biomass accumulation modified the particle characteristics. As diameter increases due to the formation of the biofilm on the 
surface of the particle the density increases. Hermanovicz and Ganczarzyk (1983) and Setiadi (1995) considered that the biofilm-wet density is equal to $1000 \mathrm{~kg} / \mathrm{m}^{3}$. Average specific density of biocovered particles was found to be increased from 870 to $960 \mathrm{~kg} / \mathrm{m}^{3}$ with increasing biofilm thickness.

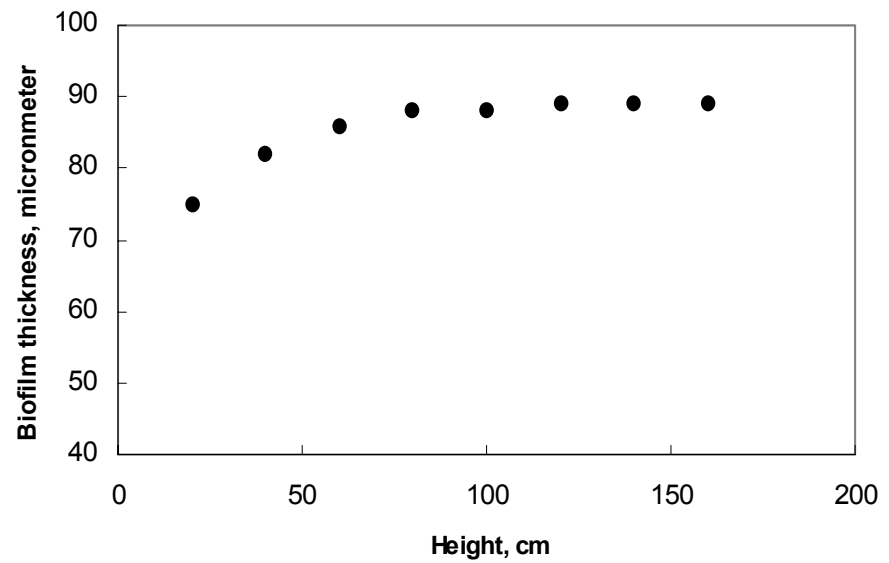

Fig. 4 Profile of the biofilm thickness by reactor height, $\mathrm{h}=0$ at top of the bed.

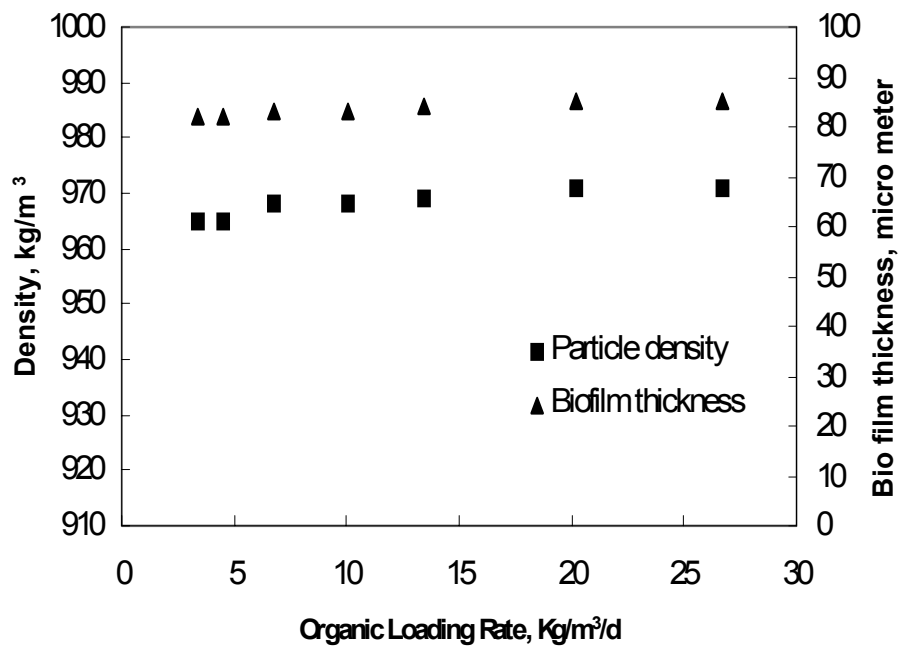

Fig.5 Biomass on the surface of particles at different OLR

Particles without biofilm presented the lowest bed expansion rate. At the same air velocity, bed expansion increased as biofilm thickness increased. This may be attributed to (i) Biofilm accumulation enlarges particles, and thus, original bed expansion is modified; and (ii) Terminal settling velocity decreases as particle density increases which means that microbial growth attachment would provoke a greater bed expansion rate at the same fluidization velocity (Garcia - Calderon et al., 1998).

Conclusion: The experiments were conducted in a fluidized bed reactor with low-density biomass support at various hydraulic retention time and for different initial substrate concentrations. From the present study, it was found that the bioreactor with low-density particles can be utilized for the treatment of starch industry wastewater. The results were summarized as follows.

- The continuous degradation study was carried out at an optimized bed height and air flow rate. The parameters varied were initial substrate concentration (2250, 4475, 6730 and $8910 \mathrm{mg}$ $\mathrm{COD} / \mathrm{L})$ and hydraulic retention time (40, 32, 24, 16 and 8h).

- The performance of the reactor was studied at various organic loading rates. At low OLR $\left(<5 \mathrm{KgCOD} / \mathrm{m}^{3} / \mathrm{d}\right)$, the efficiency of the reactor was found to be greater than $90 \%$.

- At higher OLR, greater than $20 \mathrm{~kg} \mathrm{COD} / \mathrm{m}^{3} / \mathrm{d}$, the COD removal efficiency was found to be less than $60 \%$.

- The biofilm thickness was found to be constant thought the study.

Acknowledgement: The authors wish to express their gratitude for the support extended by the authorities of Annamalai University, Annamalai Nagar, India in carrying out the research work in Environmental Engineering laboratory, Department of Chemical Engineering.

\section{REFERENCES}

Al-Dibouni, M R; Garside, J (1979). Particle mixing and classification in liquid fluidized beds. Trans. Int. Chemical Engrs., 57: 94 - 103.

Arnaiz, C; Elmaleh, S; Lebrato, J; Moletta, R (2005). Start up of an anaerobic inverse turbulent bed reactor fed with wine distillery wastewater using pre-colonised bioparticles. Water Science and Technology, 51(1):153 - 158.

Choi, Y C; Kim, D S; Park, T J; Park, K K; Song, S K (1995). 
Wastewater treatment in a pilot scale inverse fluidized-bed biofilm reactor. Biotechnology Techniques, 9 (1):35 - 40.

Garcia-Calderon, D; Buffiere, P; Moletta, R; Elmaleh, S (1998). Influence of biomass accumulation on bed expansion characteristics of a down flow anaerobic fluidized bed reactor. Biotechnology and Bioengineering, 57 (2): 136 - 144.

Hermanovicz, S W; Ganczarczyk, J J (1983). Some fluidization characteristics of biological beds. Biotechnol. Bioeng., 25:13211330 .

Karamanev, D G (1996). Application of inverse fluidization in wastewater treatment: From laboratory to full-scale bioreactors. Environmental progress 15(3):194-196.

Karamanev, D; Nikolov, L (1987). Experimental study of the Inverse fluidized bed biofilm reactor. Canadian Journal of Chemical Engineering 65: 214-217.

Nehrukumar. V (2000). Modified rotating biological contactors for the treatment of sago wastewater. Ph.D Thesis, Annamalai University.

Nikolov, L N; Karamanev, D G (1990). The Inverse Fluidized Bed Biofilm Reactor: A New Laboratory Scale Apparatus for Biofilm Research. Journal of Fermentation and Bioengineering, 69 (4): 265 267.

Rajasimman, M; Karthikeyan, C (2004). Degradation of starch industry effluent in an inverse fluidized bed reactor. Paper presented in CHEMCON - 2004, Mumbai.
Rajasimman, M; Karthikeyan, C (2006). Treatment of starch industry effluent in an inverse fluidized bed bioreactor. Journal Applied Sciences and Environmental Management, 10(1): 39 - 44.

Setiadi, T (1995). Predicting the bed expansion of an anaerobic fluidized bed bioreactor. Wat. Sci. Tech., 31: 181- 191.

Shieh, W K; Sutton, P M; Kos, P (1981). Predicting reactor biomass concentration in a fluidized bed system. JWPCF, 53: 1574 - 1584.

Sokol, W (2001). Operating Parameters for a gas-liquid-solid fluidized bed bioreactor with a low-density biomass support. Biochemical Engineering Journal 8:203-212. 